\title{
MUTUAL COUPLING REDUCTION OF MICROSTRIP PATCH ANTENNA ARRAY USING SLOTTED GROUND STRUCTURE
}

\author{
Karthik R ${ }^{1}$, R. K. Manjunath ${ }^{2}$, H. V. Kumaraswamy ${ }^{3}$ \\ ${ }^{1}$ Department of Telecommunication Engineering, R.V. College of Engineering, Bengaluru, India \\ ${ }^{2}$ Department of Telecommunication Engineering, R.V. College of Engineering, Bengaluru, India \\ ${ }^{3}$ Department of Telecommunication Engineering, R.V. College of Engineering, Bengaluru, India
}

\begin{abstract}
In microstrip patch antenna array, the mutual coupling is very critical due to surface wave excitation. It leads to degradation in radiation pattern and reduction in gain. In this paper, a method to mitigate mutual coupling effect in an antenna array using Slotted Ground Structure (SGS) at $900 \mathrm{MHz}$ and dielectric constant 2.2 is simulated and analyzed using Ansoft HFSS 13. Simulated results show an improvement in mutual coupling, return loss and gain.
\end{abstract}

Keywords - Mutual coupling, SGS, Patch antenna array, Surface wave, Microstrip patch antenna.

\section{INTRODUCTION}

In wireless communication system, there is a demand for compact and high performance devices. Microstrip technology is used in various microwave components. One of such com microwave component is Microstrip patch antenna. It has several advantages such as low profile, lowcost, light weight, easy to fabricate and ease of integration with other printed circuits. Single Microstrip antenna has limitation of low gain and directivity. In order to overcome this limitation, many microstrip antennas are arranged in array. Therefore array is used where high gain and high directivity is required. Microstrip antenna array is mainly used in aerospace, satellite and radar applications.

The main problem in microstrip patch antenna array is mutual coupling effect. It is due to excitation of surface wave, space wave and near field overlapping of the array elements. Mutual coupling effect leads to element radiation pattern distortion, side lobes higher than the desired and mismatch of individual elements to their feed. But mutual coupling depends on inter element separation and it causes undesirable effects on antenna characteristics. Therefore it is necessary to reduce mutual coupling effect in microstrip patch antenna array.

There are different methods to reduce mutual coupling like Electronic Band Gap (EBG) Structure [1], UC-EBG [2], and Spiral resonators (SR) structures [3]. Even though these techniques can reduce mutual coupling up to $10 \mathrm{~dB}$, but they have some disadvantages compact and difficult to fabricate vias in EBG and cost expensive. In this paper, a simple two rectangular slots are etched in ground plane of microstrip patch antenna array.

\section{INSET FED PATCH ANTENNA}

Inset fed Rectangular Microstrip Patch antenna is designed using transmission line model at $900 \mathrm{MHz}$, dielectric constant is 2.2 and height of the substrate is $1.6 \mathrm{~mm}$. The designed antenna dimensions are as follows. The width of the antenna is $131.76 \mathrm{~mm}$, length is $111.69 \mathrm{~mm}$, and inset distance is $34.113 \mathrm{~mm}$. The designed antenna is simulated. Return loss is analyzed.

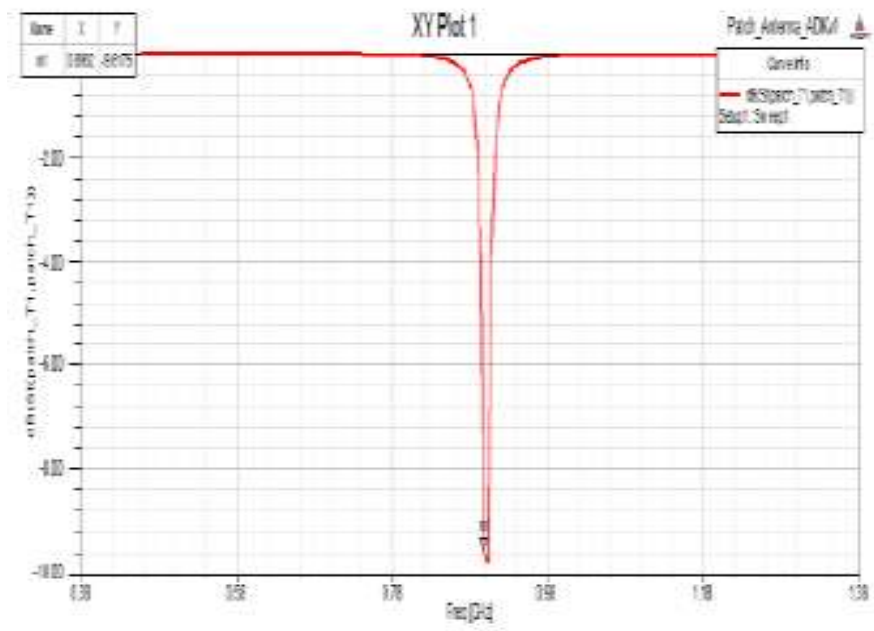

Fig 1: Return loss of an single antenna

Singe Rectangular Microstrip patch antenna is simulated and the outputs are shown in figure. Return loss is around $9.6175 \mathrm{~dB}$ at resonating frequency $0.8932 \mathrm{MHz}$.

\section{SIMULATED RESULTS OF MICROSTRIP PATCH ARRAY WITHOUT SLOTS}

Two inset fed rectangular microstrip patch antennas are separated by distance $0.75 \lambda$ is designed and simulated. The results are shown below 


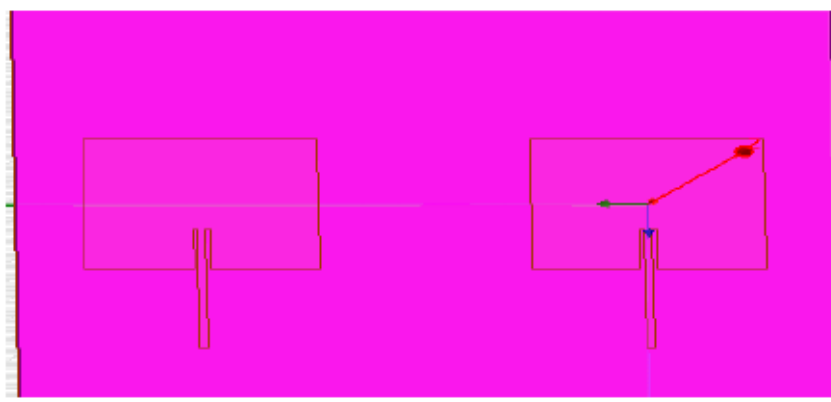

Fig 2: Microstrip Antenna Array without slots

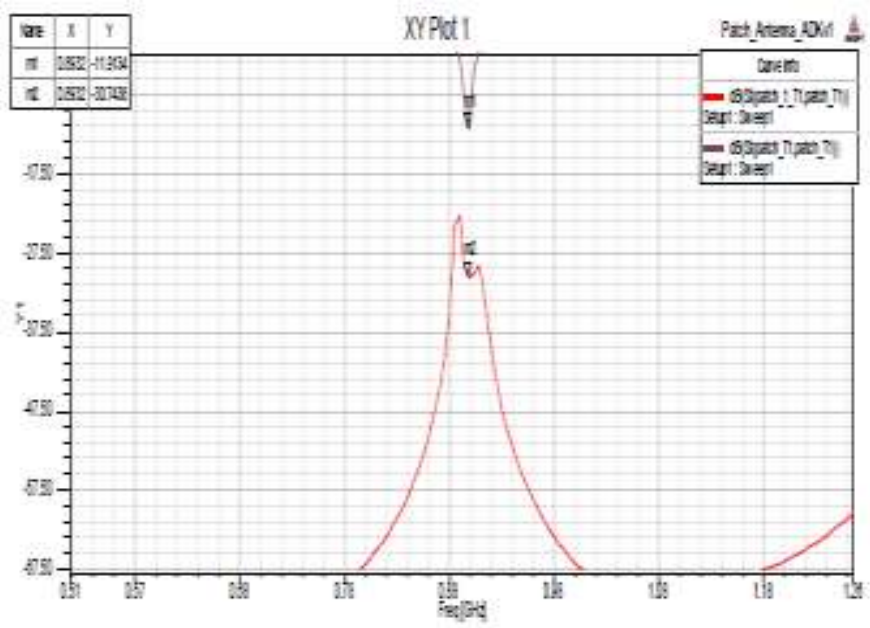

Fig 3: Return loss and S21 of Microstrip Antenna Array without slots

Figure 2 shows Microstrip patch antenna array without slots and figure 3 shows return loss of $-11.9134 \mathrm{~dB}$ and Mutual coupling around $-30.7438 \mathrm{~dB}$ and Gain is $7.9756 \mathrm{~dB}$

\section{SIMULATED RESULTS OF MICROSTRIP PATCH ARRAY WITH SLOTS}

Two rectangular slots are etched on the ground plane. These two slots are etched between two antennas. Rectangular slot dimensions are as follows, width of the slot is $0.06 \lambda$ and length of the slot is same as the patch length. The patch antenna and rectangular slot is separated by a distance of $0.03 \lambda$.

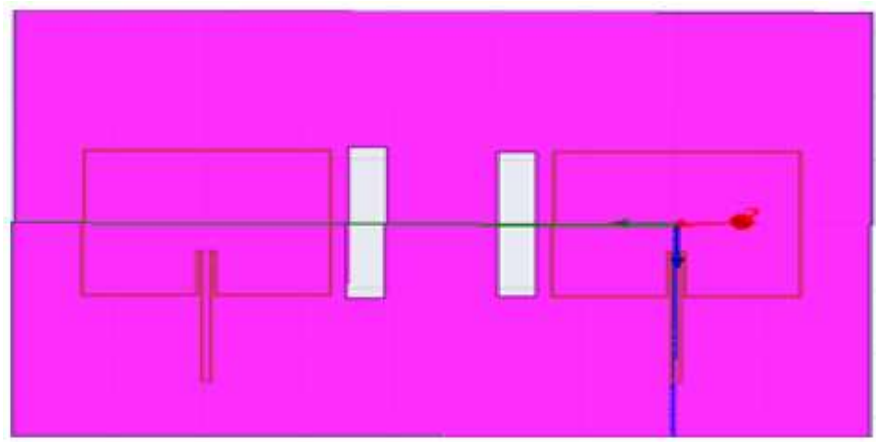

Fig 4: Microstrip Patch Array with two 0.06 $\lambda$ Rectangular Slots

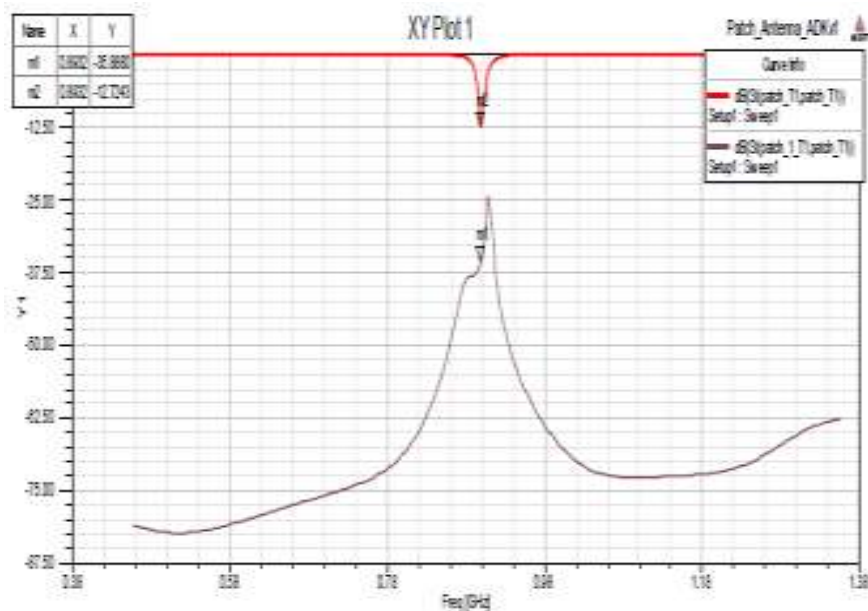

Fig 5: Return Loss and S21 of Microstrip Antenna Array with Slots

Simulated results shows that return loss is $-12.7243 \mathrm{~dB}$, mutual coupling is $-35.880 \mathrm{~dB}$ and gain is $8.0302 \mathrm{~dB}$ is achieved using two rectangular slots on ground plane in Microstrip antenna array.

\section{COMPARISON OF RESULTS OF}

\section{MICROSTRIP PATCH ANTENNA ARRAY} USING WITH AND WITHOUT SLOTS

Table 1: Comparison of parameters of antenna using with

\begin{tabular}{|c|l|l|l|}
\hline \multicolumn{5}{|c|}{ and without slots } \\
\hline Parameters & $\begin{array}{l}\text { Without } \\
\text { Slots(dB) }\end{array}$ & $\begin{array}{c}\text { With } \\
\text { Slots (dB) }\end{array}$ & \multicolumn{1}{c|}{ Comments } \\
\hline $\begin{array}{c}\text { Mutual } \\
\text { Coupling }\end{array}$ & -30.7438 & -35.880 & $\begin{array}{l}\text { By using slots } \\
\text { Mutual coupling is } \\
\text { reduced to 5.1362 } \\
\text { dB }\end{array}$ \\
\hline Return Loss & -11.9134 & -12.7243 & $\begin{array}{l}\text { Return loss is } \\
\text { increased by } \\
0.8109 \text { dB }\end{array}$ \\
\hline Gain & 7.9756 & 8.0302 & $\begin{array}{l}\text { Gain is increased } \\
\text { by 0.0546 dB }\end{array}$ \\
\hline
\end{tabular}

From the above table, it shows that by using two rectangular slots on ground plane of an antenna array we can reduce the mutual coupling effect by $5 \mathrm{~dB}$, return loss increased by $0.8109 \mathrm{~dB}$ and gain is increased by $0.0546 \mathrm{~dB}$.

\section{CONCLUSION}

Even though many techniques like EBG, DGS, UC-EBG and Spiral Resonator (SR) are used to reduce the mutual coupling effect in antenna array. These techniques have their own disadvantages. For example, EBG is complicated structure, difficult to fabricate and cost expensive. In this paper, Slotted Ground Structure (SGS) is used to reduce the mutual coupling effect in an antenna array. Advantages of SGS are easy to fabricate and cost effective. Simulation is carried by Ansoft HFSS 13. By using SGS Mutual coupling is reduced by $5 \mathrm{~dB}$. Because of its simple structure it can be used effectively to increase the performance of microstrip antenna array. 


\section{REFERENCES}

[1]. F.Benikhlef, N. Boukli-Hacen,"Mutual coupling Reduction in patch antenna Arrays Using EBG Structure" IJCSI, Vol.9, Issue 4, No 3, pp. 265-269, july2012.

[2]. Hossein Sarbandi Farahani, Mehdi Veysi, Manouchehr Kamiah, and Alireza "Mutual Coupling Reduction in Patch Antenna Arrays Using a UC-EBG Superstrate" ieee Antennas and Wireless propagation letters, Vol. 9, pp. 5759, 2010.

[3]. Przemyslaw Gorski, Pawel Kabacik N., "Effect of Passive Spiral Resonators on Suppression of Mutual Coupling Between Microstrip Antenna Elements" GeMiC 2014 March 10-12, 2014, Aachen, Germany.

[4]. S. -L Zuo, Y.-Z Yin, W.-J Wu, Z.-Y Zhang, J.Ma, "Investigations of reduction of mutual coupling between two planer monopoles using two $\lambda / 4$ slots", Progress in electromagnetics research letters. Vol.19, pp. 9-18, 2010

[5]. A.B Abdual Rahman, "Coupling reduction of antenna array elements using small Interdigital capacitor loaded slots", Progress in electromagnetics research letters, Vol. 27, pp. 15-26, 2012

[6]. F.Y. Zulkifli, E.T Rahardjo, B. Hartanto, "Mutual coupling reduction using dumbbell defected ground structure for multiband microstrip antenna array", Progress in electromagnetic research, Vol.13, pp. 29-40, 2010.

[7]. Farzad Mohajeri, Zeinab Danesh, "Reduction of mutual coupling and gain improvement using Step elewctromagnetic Band gap Strcture", IJARE, Vol.2, Issue 9, 2013.

[8]. Martin Gimersky, Jens Bornemann, "Investigation of mutual coupling effect on the radiation pattern of rectangular patch antennas", IEEE, pp. 1194-1196, 1992.

[9]. M.F Abedin, M.Ali, "Effect of smaller unit cell planer EBG Structure on the mutual coupling of the printed dipole array", Ieee antennas and wireless letters, Vol.4, pp. 274276,2005 